\title{
Synthesis of multi wall carbon nanotubes based on zirconium oxide as supported material and its application as nanosorbent for copper ions removal
}

\author{
El Nemr A. ${ }^{1}$, Serag E. ${ }^{1}$, Fathy S. ${ }^{2}$, Hamid F.A. ${ }^{2}$ and El-Maghraby A. ${ }^{3 *}$ \\ ${ }^{1}$ Marine Pollution Department, Environmental Division, National Institute of Oceanography and Fisheries, Kayet Bey, Elanfoushy, \\ Alexandria, Egypt \\ 2Department of Biochemistry, Faculty of Science, Ain Shams University, Cairo, Egypt \\ ${ }^{3}$ Fabrication Technology Research Department, Advanced Technology and New Materials Research Institute, City of Scientific Research \\ and Technological Applications, Borg El-Arab, Alexandria, Egypt \\ Received: 24/09/2021, Accepted: 21/10/2021, Available online: 03/11/2021 \\ *to whom all correspondence should be addressed: e-mail: maghrabyazza@yahoo.com \\ https://doi.org/10.30955/gnj.004019
}

Graphical abstract
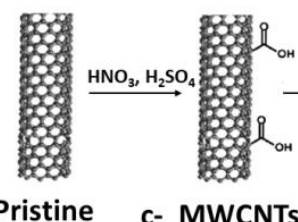

Pristine c- MWCNTs MWCNTs

\section{Abstract}

Water pollution caused by various toxic contaminants has become one of the world's most serious issues. Nanotechnology has received a lot of attention in recent decades, and various nanomaterials for water remediation have been developed. For this purpose, MWCNTs were directly synthesized using a chemical vapor deposition process, which was then purified and functionalized using an acid treatment. At various temperatures, the synthesis of MWCNTs by chemical vapor deposition (CVD) of acetylene is investigated. The wet impregnation method is used to prepare catalysts using $\mathrm{Fe} / \mathrm{Co}$ as a catalyst in the presence of zirconium oxide and aluminum oxide as support materials. Zirconium oxide was found to be a good support material for the deposition of high-purity MWCNTs with high yield $88.9 \%$. The effect of growing time and temperature on carbon yield was investigated, and it was discovered that the amount of MWCNTs deposited increased as reaction time increased, with the optimum temperature for the reaction being $700{ }^{\circ} \mathrm{C}$. The effect of temperature on the crystal size of synthesized MWCNTs was investigated using XRD, and it was found that the crystallite size declined as the temperature goes up. SEM and TEM were used to examine the structure and purity of synthesized MWCNTs at various temperatures. The MWCNTs that were synthesized have a web-like network structure, a homogeneous distribution on the catalyst surface, and a smooth surface. The prepared CNTs were purified by chemical oxidation, and the effect of acid treatment on the surface of the CNTs was investigated using XRD and FTIR. The functionalized CNTs were used for copper ion adsorption, achieving an adsorption potential of 238.09 $\mathrm{mg} / \mathrm{g}$ and a high regeneration efficiency.

Keywords: Aluminum oxide, carbon nanotube, chemical vapor deposition, copper ions, zirconium oxide.

\section{Introduction}

Carbon nanotubes (CNTs) play a role in a number of scientific and technical fields (Burakova et al., 2018). Nanoelectronics, nanosensors, photovoltaics, and chemical sensing are examples of these, since they have special electrical and thermal conductivity properties. Because of their high surface area and porous nature, CNTs have the potential to play a role in water purification (Anzar et al., 2020).

CNTs are made up of graphene sheets that have been rolled up to form hollow cylindrical tubes (Arora and Attri, 2020). There are three types of carbon nanotubes (CNTs). Single-walled carbon nanotubes (SWCNTs) have a singlecylinder with a standard diameter of $1.4 \mathrm{~nm}$, while double-walled carbon nanotubes (DWCNTs) and multiwalled carbon nanotubes (MWCNTs) have concentric cylinders with an inter-tube spacing of $0.34 \mathrm{~nm}$ and a typical diameter ranging from $2 \mathrm{~nm}$ to $30 \mathrm{~nm}$, according to the rolling up of graphene sheets. The lengths of SWCNTS and MWCNTs vary from a few micrometres to several centimetres. CNTs have a strength of thirty to one hundred times that of steel, although their density is around one-sixth that of steel. CNTs have an elastic modulus of around 1.2 TPa, which is identical to the diamond's elastic modulus. Otherwise, SWCNTs have a density of about $1.33-1.40 \mathrm{~g} / \mathrm{cm}^{3}$, which is about half that of aluminium, and their thermal conductivity $(6000 \mathrm{~W} / \mathrm{m}$ 
$\mathrm{K}$ at room temperature) is roughly double that of diamond. Furthermore, their electrical current has a larger magnitude than copper (Hussein et al., 2014; Patel et al., 2021).

For the development of CNTs, various synthetic methods have been established, such as laser vaporisation, which operates at room temperature but yields low yields and is otherwise a high-cost technique. The second approach for producing CNTs is arc discharge, which produces highquality and low-cost CNTs but necessitates a hightemperature environment (Dhorea et al., 2018). Although both arc discharge and laser ablation methods produce CNTs, purification is required (Sari et al., 2018). The chemical vapor method (CVD) is the most suitable method for producing CNTs with high yield, high purity, and regulated growth. It is a simple technique that produces CNTs of high quality and quantity, with a realistic yield of (>75 percent) (Yang et al., 2019; Tchudan et al., 2019). The most important catalysts for the CVD system of CNT growth are cobalt (Co), iron (Fe), and nickel (Ni) (Wanga et al., 2019).

All of the parameters and conditions of CNT fabrication, including the supporting materials that contribute to the catalyst for CNT development, are still being investigated. During the CVD process, the presence of support materials has a significant effect on the high quality of the grown CNTs. Peigney et al. (1997), for example, used Fealumina nanocomposite as a catalyst to produce single and multiwall carbon nanotubes (Peigney et al., 1997). The use of porous $\mathrm{MgO}$ as a support material greatly improved the yield of SWCNTs grown using silica/alumina supported material with $\mathrm{Fe}, \mathrm{Co}$, or $\mathrm{Ni}$ oxide as catalysts, according to the researchers (Cassell et al., 1999; Qingwen et al., 2002).

Heavy metal contamination in water, such as cadmium, zinc, and copper, is a serious concern to human health and the environment. As a result, many attempts are made to reduce water contamination. Toxin removal strategies include chemical precipitation, ion exchange, and electrolytic reduction, reverse osmosis, advanced oxidation, membrane technology, and biological treatments (Mwafya and Mostafa, 2020). The methods listed are costly and produce a lot of sludge, while the adsorption method is a good option for water treatment because it is both cost-effective and reliable (Mwafya and Mostafa, 2020). Adsorbents such as activated carbon, zeolites, clays, and carbon nanotubes are used to eliminate toxic contaminants from water (Ihsanullah et al., 2020). Activated carbon, zeolites, and clays (Ihsanullah et al., 2020).

Carbon nanotubes have been found to be among the most successful materials in the treatment of water and the adsorption of heavy metals such as copper, cadmium, and lead in many published studies. It was also effective in both polar and nonpolar organic molecules (Hanbali et al., 2020). This was due to the various physical and chemical interactions that MWCNT would have such as Covalent bonding, hydrogen bonding ( $\mathrm{Du}$ et al., 2014), and electrostatic interactions (Chen et al., 2014).
CNT functionalizations are important for increasing the performance and compatibility of CNTs as adsorbents. As compared to non-functionalized CNTs, the acid modified CNTs have a higher adsorption capacity in almost all studies. This may be due to an electrostatic attraction between the divalent heavy metal ions and the negative charge on the CNTs surface after acid treatment (Abbas et al., 2016).

The effects of zirconium oxide as a supporting material in the synthesis of MWCNTs using Fe/Co catalysts by CVD of acetylene gas are described in this paper. The morphological features of the grown MWCNTs were analyzed using TEM, SEM, and XRD to determine the optimum conditions for MWCNT fabrication. Furthermore, the MWCNTs were functionalized and used as a nanosorbent to remove copper ions from aqueous solutions.

\section{Materials and methods}

\subsection{Chemicals}

The used chemicals were iron (III) nitrate, cobalt nitrate, aluminum oxide, and zirconium oxide were obtained as the analytical grade from Sigma-Aldrich and used without further purification. Nitric acid, sulfuric acid, sodium hydroxide, copper sulfate pentahydrate were purchased from El-Nasr Co. Egypt, and were used without further purification.

\subsection{Preparation and characterization of carbon nanotube catalysts}

The support materials were impregnated in salt solutions of Fe $\left(\mathrm{NO}_{3}\right)_{3} \cdot 9 \mathrm{H}_{2} \mathrm{O}$ and $\mathrm{Co}\left(\mathrm{NO}_{3}\right)_{2} \cdot 6 \mathrm{H}_{2} \mathrm{O}$ to create catalysts. Aqueous solutions were made by dissolving a 1:1 molar ratio in distilled water in a limited volume. After stirring until the salts in the solution were homogeneous, zirconium oxide $\mathrm{ZrO}_{2}$ was added in a molar ratio of Fe: $\mathrm{Co}$ : $\mathrm{ZrO}_{2}$ of $2.5 \%, 2.5 \%$, and $95 \%$, respectively. The resulting catalyst $\left(\mathrm{Fe} / \mathrm{Co} / \mathrm{ZrO}_{2}\right)$ was dried in a $125^{\circ} \mathrm{C}$ oven for 12 hours. The dried material was then ground in a mortar to make a fine powder, which was then calcined in a tube furnace at $600^{\circ} \mathrm{C}$ under $\mathrm{N}_{2}$ gas flow.

In the same way, $\mathrm{Fe} / \mathrm{Co}$ supported on $\mathrm{Al}_{2} \mathrm{O}_{3}$ was prepared to compare the grown of MWCNT on new supported material zirconium oxide with that grown on aluminum oxide, which is commonly used in CNT preparation.

X-ray Diffractometer (XRD-7000, Schimadzu Corp., Columbia, MD) with Cu-Ka radiation (D $0.154060 \mathrm{~nm}$ ) produced at $30 \mathrm{kV}$ and $30 \mathrm{~mA}$ was used to examine the catalyst samples. Scans were performed at $2^{\circ} \mathrm{C} \mathrm{min}{ }^{-1}$ for 2 values ranging from 10 to 90 degrees. The morphology of the catalysts was investigated using a scanning electron microscope (SEM) (JEOL, Model JSM 6360LA, Japan). The surface area of both catalysts was measured using the Belsorp-mini-II from Japan.

\subsection{Optimization of MWCNT synthesis}

Using the two prepared catalysts, MWCNTs were produced by pyrolysis of acetylene gas in a horizontal tube furnace at different temperatures $\left(700,800\right.$, and $\left.900^{\circ} \mathrm{C}\right)$, 
different nitrogen flow rates $\left(75,120 \mathrm{ml} . \mathrm{min}^{-1}\right)$, and different reaction times (40 $\mathrm{min}, 60 \mathrm{~min}$ ).

The reactor (consisting of a $40 \mathrm{~mm}$ radius $70 \mathrm{~cm}$ length of quartz tube heated by an electrical tube furnace with a temperature controller at a rate of $50^{\circ} \mathrm{C} \mathrm{min}{ }^{-1}$ to reach the target temperature and an additional 10 minutes to enable the furnace to regulate the flow of nitrogen at $(75$, and $\left.120 \mathrm{ml} \mathrm{min} \mathrm{m}^{-1}\right)$. The reactor tube was then filled with acetylene $\left(\mathrm{C}_{2} \mathrm{H}_{2}\right)$ at rates of 30 and $50 \mathrm{ml} \mathrm{min}^{-1}$ for 40 and 60 minutes, respectively. A mass flow controller was used to monitor the flow of gases. The samples were then cooled to room temperature under a $40 \mathrm{ml} \mathrm{min}^{-1}$ nitrogen flow and defined as stated below.

The yield of carbon deposits was calculated by measuring the catalysts before and after MWCNT deposition. For accurate measurements, the same weight of catalyst used in MWCNT growth was treated in the tube furnace without acetylene gas.

Equation 1 (Kathyayini et al., 2004; El-Maghraby et al., 2014) was used to measure the weight gain during the reaction.

$$
\text { Carbon deposit \% }=\frac{M_{3}-\left(M_{1}-M_{2}\right)}{M_{3}} \times 100
$$

Where $M_{1}$ is the initial weight of the catalyst, $M_{2}$ is the weight loss of the catalyst at the reaction temperature and $M_{3}$ is the weight of the carbon deposit and the catalyst.

Scan electron microscope (SEM) (JEOL, Model JSM 6360LA, Japan) and transmission electron microscopy (TEM) (JEOL-JEM2100) were utilized for displaying the distribution of MWCNTs in the carbon deposit.

\subsection{Functionalization of the synthesized MWCNTS}

Carboxylation of MWCNTs (c-MWCNTs) was carried out according to (Pham et al., 2011), where MWCNTs were dispersed through ultrasonication in a mixture solution of concentrated sulfuric acid $\mathrm{H}_{2} \mathrm{SO}_{4}$ and nitric acid $\mathrm{HNO}_{3}$ with a volume ratio of $3: 1$, and the carboxylic function groups on the MWCNTs surface were investigated using Fourier transform infrared spectroscopy FTIR and X-Ray diffraction XRD (Schimadzu-7000).

\subsection{Removal studies of copper ions by c-MWCNT}

Different quantities of c-MWCNTs were applied to aqueous copper ion solutions, and the solution was shaken for the required duration at $200 \mathrm{rpm}$ on a rotary shaker. The effect of $\mathrm{pH}$, contact time, adsorbent, and copper ion concentrations on the copper ion removal process was investigated.

The concentrations of copper ions were calculated using a spectrophotometer set to $550 \mathrm{~nm}$ (Sarker and Ullaha, 2013). Equation 2 (Ajitha et al., 2017) was used to quantify the extracted copper ions at equilibrium qe (mg/g).

$$
\mathrm{q}_{\mathrm{e}}=\frac{(\boldsymbol{C o}-\boldsymbol{C e})}{m} \times V
$$

Where $C_{0}$ is the initial copper ion concentrations $(\mathrm{mg} / \mathrm{L})$, $\mathrm{Ce}$ is equilibrium copper ions Concentrations $(\mathrm{mg} / \mathrm{L}), \mathrm{V}$ is the volume $(L)$ of the adsorbate solution and $m$ represents the adsorbent mass in $\mathrm{g} / \mathrm{L}$.

\subsection{Adsorption isotherm of $\mathrm{Cu}$ ions}

The relationship between the adsorbed copper ions per unit mass of c-MWCNT and their equilibrium concentrations was evaluated using Langmuir, Freundlich.

The Langmuir isotherm model describes the formation of a uniform monolayer adsorbate on the outer surface of cMWCNTs (Langmuir, 1916).

The Langmuir isotherm equation can be described in equation (3):

$$
\frac{C_{e}}{q_{e}}=\frac{1}{k_{a} Q_{m}}+\frac{1}{Q_{m}} C_{e}
$$

$\mathrm{C}_{e}$ is the equilibrium concentration of $\mathrm{Cu}$ ions in $\mathrm{mg} / \mathrm{L}$, while qe $(\mathrm{mg} / \mathrm{g})$ is represents the number of $\mathrm{Cu}$ ions adsorbed at equilibrium, $Q_{m}(\mathrm{mg} / \mathrm{g})$ is the maximum capacity of monolayer coverage and $k_{a}(L / m g)$ is the constant of Langmuir isotherm.

On the otherhand Freundlich isotherm model describes the adsorption on a heterogeneous surface with ununiform energy (Freundlich, 1906). The Freundlich isotherm equation can be described in equation (4):

$$
\log \boldsymbol{q}_{e}=\log \boldsymbol{k}_{f}+\frac{1}{n} \log c_{e}
$$

$\mathrm{K}_{\mathrm{f}}(\mathrm{mg} / \mathrm{g})$ is the Freundlich isotherm constant and $\mathrm{n}$ is the adsorption intensity.

\subsection{Kinetic parameters for Cu ions adsorption}

At an initial concentration of $200 \mathrm{ppm}$ for copper ion and $10 \mathrm{mg}$ of c-MWCNT, the kinetics of adsorption were investigated for contact times of 10 to 90 minutes. During the entire contact time, the samples were agitated at 180 rpm. Following agitation, the samples were centrifuged at $3900 \mathrm{rpm}$ for 20 minutes before being filtered (pore size $0.45 \mathrm{~mm}$ ) and the remaining ion concentrations measured. Two kinetic models are tested to match experimental results, including the pseudo-first-order equation (5) (Lagergren, 1898), the pseudo-second-order equation (6) (Ho cKay, 1999).

$$
\begin{aligned}
& \log \left(q_{e}-q_{t}\right)=\log q_{e}-\frac{K_{1}}{2.303}(t) \\
& \frac{t}{q_{t}}=\frac{1}{K_{2} q_{e}^{2}}+\frac{1}{q_{e}}(t)
\end{aligned}
$$

Where $\mathrm{q}_{\mathrm{e}}$ and $\mathrm{q}_{\mathrm{t}}$ are the adsorption capacities at equilibrium and time $\mathrm{t}$, respectively $(\mathrm{mg} / \mathrm{g})$, and $\mathrm{k}_{1}\left(\mathrm{~min}^{-1}\right)$ is the pseudo first order adsorption rate constant, and $k_{2}$ ( $\mathrm{g} / \mathrm{mg} \mathrm{min}$ ) is the pseudo second order adsorption rate constant.

\subsection{Regeneration test}

One-step desorption experiments were performed to assess the possibility of c- MWCNT reusability for future 
use. $\mathrm{HCl}$ was chosen as the eluent agent in this study because it is the most efficient eluent for desorbing loaded ions from adsorbent surfaces (Smiciklas et al., 2006; Gautam et al., 2014). To test the sorbents' reusability, copper ions at an initial concentration of 200 ppm were used.

Following batch adsorption tests, each sample's supernatant was decanted, and the metal-loaded samples Table 1. BET results of $\mathrm{Fe} / \mathrm{Co} / \mathrm{Al}_{2} \mathrm{O}_{3}$, and $\mathrm{Fe} / \mathrm{Co} / \mathrm{ZrO}_{2}$ catalysts were dried at $100{ }^{\circ} \mathrm{C}$ for 24 hours. A total of $50 \mathrm{~mL}$ of 0.01 $\mathrm{M} \mathrm{HCl}(\mathrm{pH} 2)$ was added to the dried samples, which were then shaken for 24 hours at $180 \mathrm{rpm}$ and centrifuged for 20 minutes at $3900 \mathrm{rpm}$. The next adsorption cycle began with the used sorbents being dried in an oven at $60{ }^{\circ} \mathrm{C}$ for 24 hours. The adsorption-desorption tests were carried out three times. Each test was run twice, and the mean was calculated.

\begin{tabular}{cccc}
\hline Catalyst & $\mathbf{S}_{\mathrm{BET}}\left(\mathbf{m}^{\mathbf{2}} \mathbf{~}^{-\mathbf{1}}\right)$ & Pore volume $\left(\mathbf{c m}^{\mathbf{2}} \mathbf{~ g}^{-\mathbf{1}}\right)$ & Pore diameter $(\mathbf{n m})$ \\
\hline $\mathrm{Fe} / \mathrm{Co} / \mathrm{Al}_{2} \mathrm{O}_{3}$ & 2.59 & $7.164 \times 10^{-3}$ & 11.026 \\
\hline $\mathrm{Fe} / \mathrm{Co} / \mathrm{ZrO}_{2}$ & 11.67 & $63.4 \times 10^{-3}$ & 21.729 \\
\hline
\end{tabular}

\section{Results and discussion}

\subsection{Characterization of the prepared catalysts \&} carbonaceous materials

The XRD pattern of catalysts $\mathrm{Fe} / \mathrm{Co} / \mathrm{Al}_{2} \mathrm{O}_{3}$, and $\mathrm{Fe} / \mathrm{Co} / \mathrm{ZrO}_{2}$ are shown in Figure $1 a$ and $b$. The peaks of the $\mathrm{ZrO}_{2}$ are clearly detected in the range (27-32) $2 \theta$ corresponding to lines (111, and 110), the presence of both tetragonal and monoclinic $\mathrm{ZrO}_{2}$ phases was suggested. At room temperature, pure $\mathrm{ZrO}_{2}$ exists as a monoclinic phase $\left(\mathrm{mZrO}_{2}\right)$, but as the temperature rises, it transforms into tetragonal zirconia $\left(\mathrm{t}-\mathrm{ZrO}_{2}\right)$ and cubic zirconia $\left(\mathrm{c}-\mathrm{ZrO}_{2}\right)$. On the other hand, the addition of iron and cobalt stabilised the teteragonal phase of zirconia and prevented the transition from the tetragonal to the monoclinic phase during calcination, demonstrating the good dispersion of iron and cobalt oxides on the surface of $\mathrm{ZrO}_{2}$ (Ohtsuka, 2003; Legorreta et al., 2008). The corresponding (511) line defines the peak of Cobalt oxide at $59.62 \theta$ Otherwise, the characteristic peaks for Iron oxide at 24.9 and $40.82 \theta$ corresponding to lines (012 and 113), and $67.32 \theta$ corresponding to line (522) for $\gamma-\mathrm{Al}_{2} \mathrm{O}_{3}$.
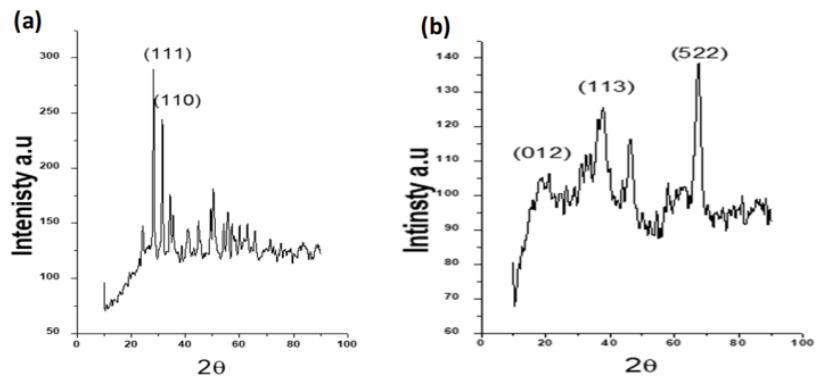

Figure 1. XRD patterns of (a) Fe $\backslash \mathrm{Co} / \mathrm{ZrO}_{2}$ (b) catalyst Fe/Co / $\mathrm{Al}_{2} \mathrm{O}_{3}$.

The scale of both catalysts was confirmed to be in the nanometer range via SEM observation as seen in Figure 2, the average size of $\mathrm{Fe} / \mathrm{Co} / \mathrm{Al}_{2} \mathrm{O}_{3}$ around $19 \mathrm{~nm} \pm 0.84$, while the size of $\mathrm{Fe} / \mathrm{Co} / \mathrm{ZrO}_{2}$ around $78 \pm 0.63 \mathrm{~nm}$.

Figure 3 shows that the surface area of the $\mathrm{Fe} / \mathrm{Co} / \mathrm{ZrO}_{2}$ catalyst is greater than that of the $\mathrm{Fe} / \mathrm{Co} / \mathrm{Al}_{2} \mathrm{O}_{3}$ catalyst, which agrees with the XRD result because the transformation of zirconia from tetragonal to monoclinic phase during catalyst calcination was accompanied by a change in surface area (Calafat, 1998). Besides that, both catalysts obey IV behavior, with pore diameters ranging from 2 to $50 \mathrm{~nm}$, indicating that they were mesoporous materials (Table 1 ).

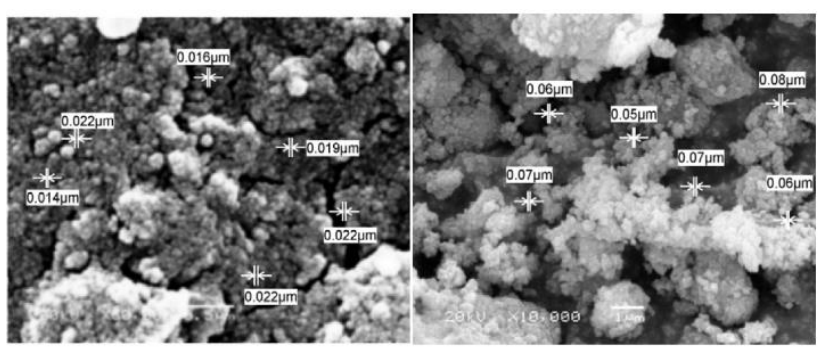

(a)

(b)

Figure 2. Scanning electron micrograph (SEM) of (a) $\mathrm{Fe} / \mathrm{Co} / \mathrm{Al}_{2} \mathrm{O}_{3}$ and (b) $\mathrm{Fe} / \mathrm{Co} / \mathrm{ZrO}_{2}$.

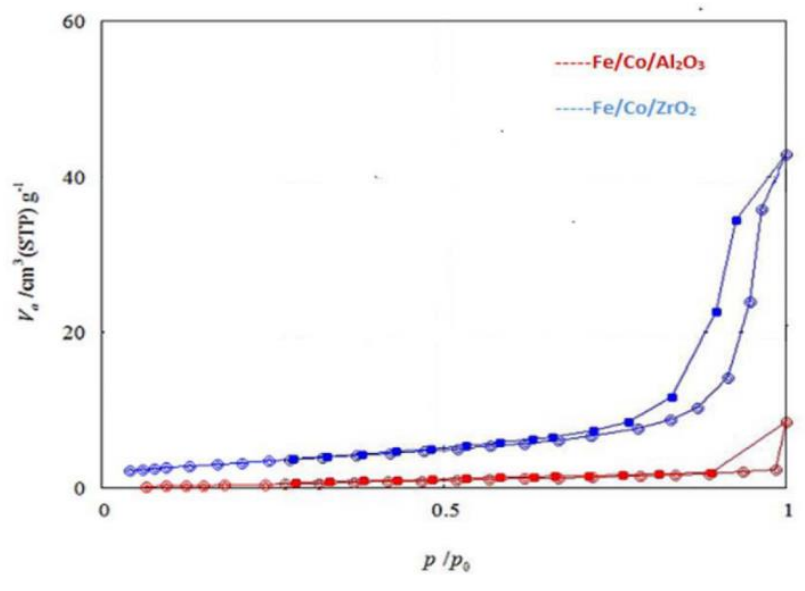

Figure 3. Plot of the isotherms $\mathrm{Fe} / \mathrm{Co} / \mathrm{Al}_{2} \mathrm{O}_{3}$, and $\mathrm{Fe} / \mathrm{Co} / \mathrm{ZrO}_{2}$ catalysts powders measured at temperature $77 \mathrm{~K}$.

The key factors that influenced the yield of MWCNTs were catalyst-metal support, synthesis period, temperature, carbon source (acetylene) flow, and nitrogen gas flow, according to the regression study. The experiments were carried out at two different acetylene flow rates (25 and $50 \mathrm{~mL} \mathrm{~min}^{-1}$ ) and for different reaction times (40 and 60 minutes), pointing to a better conversion of acetylene into MWCNTs at a flow rate of $50 \mathrm{~mL} \mathrm{~min}^{-1}$ for 60 minutes, as reported in (Table 2). It was observed that the MWCNTs yield was increased with the increase of synthesis 
duration. The highest yield of prepared MWCNTs on both catalysts was obtained by increasing the reaction time from 40 to 60 minutes and performing the reaction at $700^{\circ} \mathrm{C}$ with a low acetylene flow rate $\left(25 \mathrm{ml} \mathrm{min}^{-1}\right)$. For all of the catalysts used, the yield of MWCNTs decreased as the rate of flow of $\mathrm{N}_{2}$ increased from 75 to $120 \mathrm{~mL} \mathrm{~min}{ }^{-1}$.
This is due to the fact that as the carrier gas flow rate increases, the contact time between the acetylene and the catalyst decreases. However, when the flow rate of acetylene gas was increased, the change in the amount of $\mathrm{N}_{2}$ flow did not show significant change in the percentage of carbon deposit.

Table 2. The yield \% of carbon deposit from acetylene decomposition on $\mathrm{ZrO}_{2}$ and $\mathrm{Al}_{2} \mathrm{O}_{3}$ supported materials at reaction temperature $700^{\circ} \mathrm{C}$.

\begin{tabular}{|c|c|c|c|c|}
\hline \multirow[t]{2}{*}{ Catalyst } & \multirow[t]{2}{*}{ Nitrogen flow $\left(\mathrm{ml} \mathrm{min}^{-1}\right)$} & \multirow{2}{*}{$\begin{array}{l}\text { Acetylene flow (ml } \\
\left.\qquad \min ^{-1}\right)\end{array}$} & \multicolumn{2}{|c|}{$\begin{array}{l}\text { The yield }(\%) \text { of Carbon deposit depending on the } \\
\text { reaction time }\end{array}$} \\
\hline & & & $40 \mathrm{~min}$ & $60 \mathrm{~min}$ \\
\hline \multirow{4}{*}{$\mathrm{Fe} / \mathrm{Co}$ on $\mathrm{ZrO}_{2}$} & 75 & 25 & 71.5 & 82.21 \\
\hline & & 50 & 86.3 & 88.9 \\
\hline & 120 & 25 & 52.1 & 60.3 \\
\hline & & 50 & 55.0 & 61.1 \\
\hline \multirow{4}{*}{$\mathrm{Fe} / \mathrm{Co}$ on $\mathrm{Al}_{2} \mathrm{O}_{3}$} & 75 & 25 & 59.1 & 64.0 \\
\hline & & 50 & 67.4 & 73.5 \\
\hline & 120 & 25 & 48.0 & 56.3 \\
\hline & & 50 & 55.9 & 71.34 \\
\hline
\end{tabular}

Table 3. The yield \% of MWCNTs at different reaction temperature

\begin{tabular}{llll}
\hline Catalyst & Temperature ${ }^{\circ} \mathrm{C}$ & Yield \% \\
\hline \multirow{3}{*}{$\mathrm{Fe} / \mathrm{Co}$ on $\mathrm{ZrO}_{2}$} & 700 & 76.0 \\
\cline { 3 - 4 } & & 800 & 64.3 \\
\cline { 2 - 3 } & & 900 & 60.0 \\
\hline & $\mathrm{Fe} / \mathrm{Co}$ on $\mathrm{Al}_{2} \mathrm{O}_{3}$ & 800 & 61.1 \\
\cline { 2 - 3 } & 900 & 59.1 \\
\hline
\end{tabular}

Table 4. Literature reaction conditions and yield \% of obtained MWCNTs

\begin{tabular}{|c|c|c|c|c|c|}
\hline \multirow{2}{*}{ Catalyst } & \multirow{2}{*}{ Carbon source } & \multicolumn{2}{|c|}{ Reaction Conditions } & \multirow{2}{*}{ Yield \% } & \multirow{2}{*}{ Ref. } \\
\hline & & Temp. ${ }^{\circ} \mathrm{C}$ & Flow Rate $\mathrm{ml} \mathrm{min} \mathrm{m}^{-1}$ & & \\
\hline $\mathrm{Fe} / \mathrm{Co} / \mathrm{Al}_{2} \mathrm{O}_{3}$ & Acetylene & 700 & 50 & 73.5 & Present work \\
\hline $\mathrm{Fe} / \mathrm{Co} / \mathrm{ZrO}_{2}$ & Acetylene & 700 & 50 & 88.9 & Present work \\
\hline $\mathrm{Fe} / \mathrm{Ni} / \mathrm{Al}_{2} \mathrm{O}_{3}$ & Ethanol & 900 & - & 68 & (Colomer et al., 2000) \\
\hline $\mathrm{Co} / \mathrm{Fe} / \mathrm{Cu}$ on $\mathrm{SiO}_{3}$ & acetylene & 700 & 8 & $71-76$ & (Fonseca et al., 1998) \\
\hline $\mathrm{Fe} / \mathrm{Co} /$ Zeolite powder & Ethanol & 800 & 5 Torr & 42 & (Maruyama et al., 2004) \\
\hline
\end{tabular}

It has previously been stated that high temperatures are associated with higher yields of carbon nanotubes, and that high temperatures have a significant impact on metal activity and the decomposition of carbon-containing gases. High temperature, on the other hand, can cause agglomeration of catalytic metal particles, which is a negative factor in CNT synthesis (El-Maghraby et al., 2014). The carbon content (MWCNT yield) which obtained from the proposed $\mathrm{Fe} / \mathrm{Co} / \mathrm{ZrO}_{2}$ and $\mathrm{Fe} / \mathrm{Co} / \mathrm{Al}_{2} \mathrm{O}_{3}$ is described in Table 3. It was also found that the best temperature for growing MWCNTs was $700{ }^{\circ} \mathrm{C}$ (Table 3). The results in this section of study are compared with that of literature in Table 4.

SEM observation of the synthesized MWCNT at different temperatures in Figure 4 reveals that the synthesized MWCNT at $700{ }^{\circ} \mathrm{C}$ with a web-like network structure and homogeneous distribution on the catalyst surface, however, as the temperature of the reaction increase from 700 to $900{ }^{\circ} \mathrm{C}$ the amorphous carbon appeared with the synthesized MWCNT as well as the diameter of the synthesized carbonaceous material increase by elevation of the reaction temperature, these results similar to that obtained by (Mohammed et al., 2017).

TEM observations for the grown MWCNTs on both catalyst at optimum conditions $\left(700^{\circ} \mathrm{C}\right.$ in Acetylene for 60 min) are in general agreement with the above results Figures 5 and 6 . The tubes formed are multiwall with a smooth surface, with only a few showing roughness, suggesting weak graphitization. On the outside of the bundle, no amorphous carbon could be found. Bamboolike structures or carbon nanoparticles were not found in the produced samples. The high quality of the synthesized MWCNTs could be explained by the good interactions between the metal phase and the support. However, the presence of catalyst particles encapsulated with grown MWCNTs suggested that MWCNTs grew from catalyst particles via a tip growth mechanism. The MWCNTs synthesized on $\mathrm{Fe} / \mathrm{Co} / \mathrm{ZrO}_{2}$ are well deformed tubes with a 
thick network, with an average diameter of 30-40 nm. This is explained by the fact that the high surface area of $\mathrm{Fe} / \mathrm{Co} / \mathrm{ZrO}_{2}$ allows for more contact between the catalyst and the carbon source, as well as a decrease in metal nanoparticle migration along the metal support surface, resulting in uniform metal distribution on the supporting material (Monshi et al., 2012).

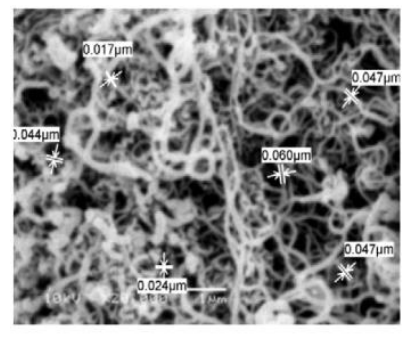

(a)

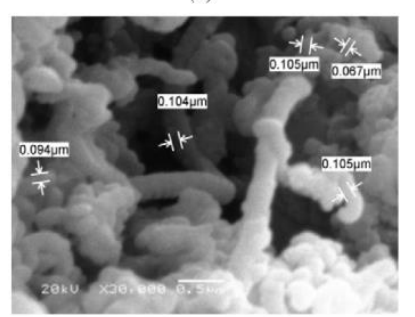

(c)

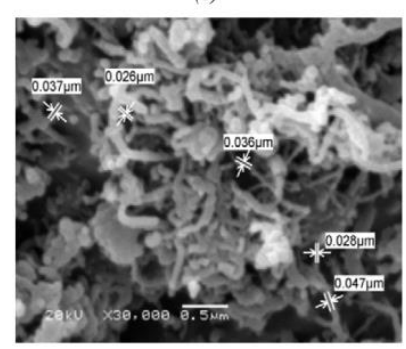

(e)

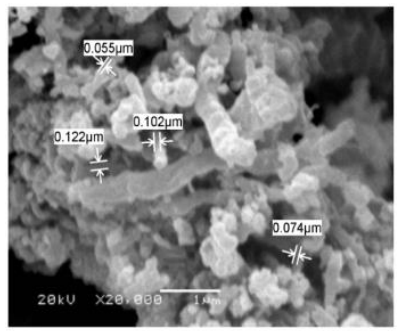

(b)

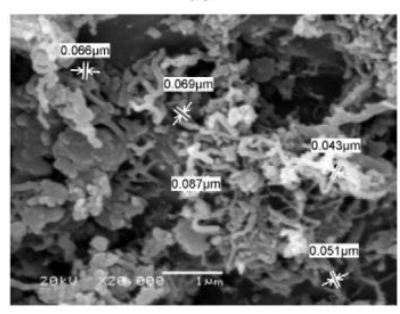

(d)

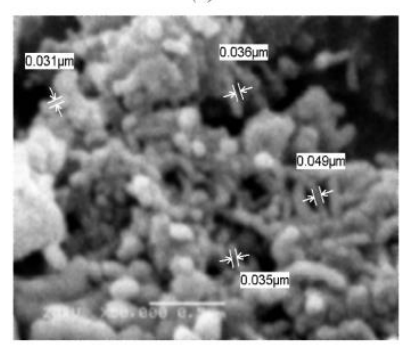

(f)
Figure 4. Scanning electron micrograph (SEM) of carbonaceous nonomaterial obtained with $\mathrm{Fe} / \mathrm{Co} / \mathrm{ZrO}_{2}$ (a) at $700{ }^{\circ} \mathrm{C}$, (b) at 800 ${ }^{\circ} \mathrm{C}$, (c) at $900{ }^{\circ} \mathrm{C}$, SEM of $\mathrm{Fe} / \mathrm{Co} / \mathrm{Al}_{2} \mathrm{O}_{3}$ (d) at $700{ }^{\circ} \mathrm{C}$, (e) at $800{ }^{\circ} \mathrm{C}$, (f) at $900^{\circ} \mathrm{C}$.

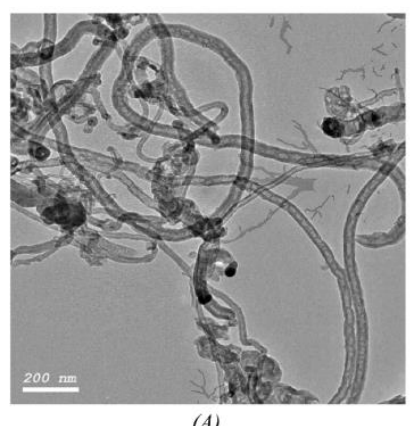

(A)

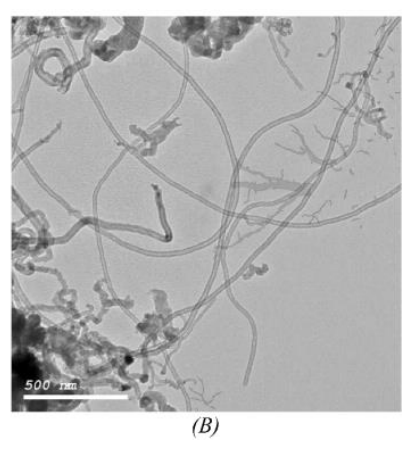

(B)
Figure 5. TEM images at magnification $200 \mathrm{~nm}(\mathrm{~A})$ and $500 \mathrm{~nm}$ (B) for MWCNTs grown on $\mathrm{Fe} / \mathrm{CO} / \mathrm{Al}_{2} \mathrm{O}_{3}$ at $700{ }^{\circ} \mathrm{C}$ in acetylene for $60 \mathrm{~min}$.

\subsection{Characterization of the functionalized MWCNT (c- MWCNT) for copper ions adsorption}

Figure 7a showed the XRD pattern of oxidized MWCNTs which were synthesized at the optimum conditions (at $700{ }^{\circ} \mathrm{C}$, acetylene gas flow $50 \mathrm{ml} / \mathrm{min}$, for $60 \mathrm{~min}$, and grown on $\mathrm{Fe} / \mathrm{CO} / \mathrm{ZrO}_{2}$. From the pattern, it was found downshifting of graphite peak at $2 \theta=26.5$ which corresponding to the (002) reflection into $2 \theta=25$ as a result of increasing in $\mathrm{sp}^{2}, \mathrm{C}=\mathrm{C}$ layer spacing (Gupta and Saleh, 2011). The diffraction peaks at $2 \theta$ of 43 and 56.8 represent the (100), (101) reflections.
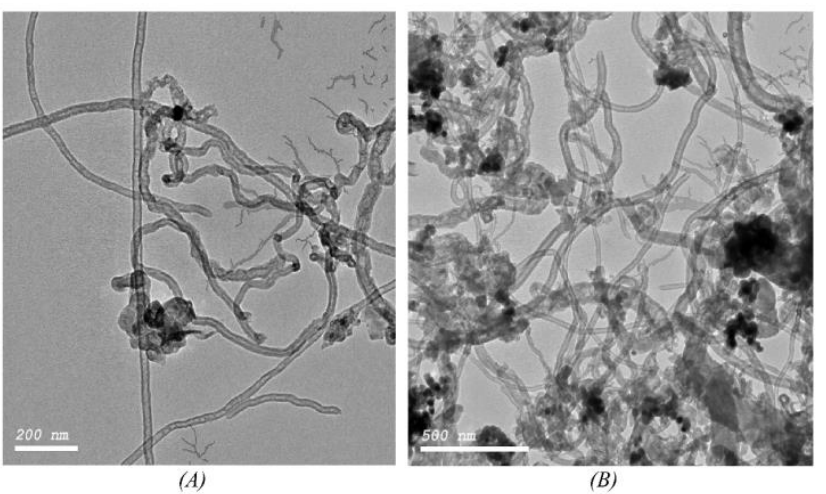

Figure 6. TEM images at magnification $200 \mathrm{~nm}(\mathrm{~A})$ and $500 \mathrm{~nm}$ (B) for MWCNTs grown on $\mathrm{Fe} / \mathrm{CO} / \mathrm{ZrO}_{2}$ at $700{ }^{\circ} \mathrm{C}$ in acetylene for $60 \mathrm{~min}$.
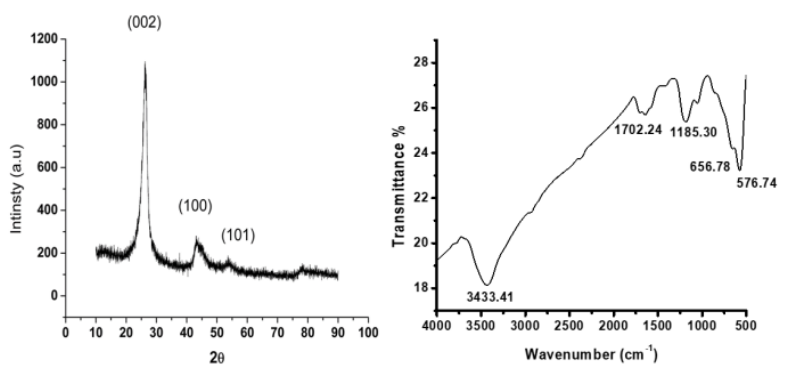

Figure 7. (a) XRD pattern of the oxidized MWCNT, (b) FTIR analysis of the oxidized MWCNT.
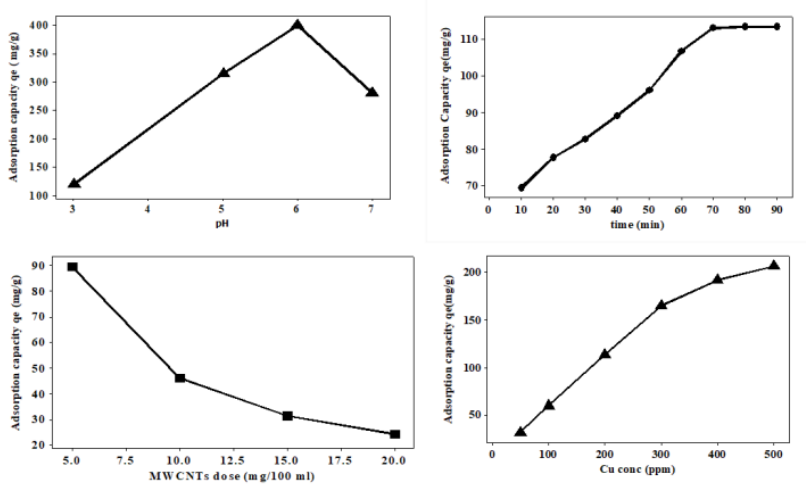

Figure 8. (a) the effect of $\mathrm{pH}$ on the adsorption of copper ions, (b) the effect of contact time on the adsorption process, (C) effect of the MWCNTs dose on the adsorption process, (d) the adsorption capacity of MWCNTs at different concentrations of Copper ions in the aqueous solutions.

Figure $7 \mathrm{~b}$ exhibits FTIR of the oxidized MWCNT, as observed the wide peak at $3433 \mathrm{~cm}^{-1}$ associated with the $\mathrm{O}-\mathrm{H}$ stretch of the hydroxyl group while the peak at $1702.24 \mathrm{~cm}^{-1}$ Refer to the stretch of the $\mathrm{C}-\mathrm{O}$ bond of the carbonyl group (El Nemr et al., 2019;, Hole et al., 2021). This assigned to the functionalization of MWCNT with the carboxyl groups. On the other side the peaks at 16433.41, and $1422.55 \mathrm{~cm}^{-1}$ assigned to $\mathrm{C}=\mathrm{O}$, and $\mathrm{C}-\mathrm{C}$ bonds (Yan et al., 2007; Wang et al., 2021) FTIR confirmed the 
functionalization of MWCNT with $(\mathrm{COOH})$ as the main function groups on the MWCNT surface represented by the carbonyl groups, and the hydroxyl groups that are attached to the same carbon atom.

\subsection{Adsorption studies}

\subsubsection{Effect of $\mathrm{pH}$ and contact time on copper ions adsorption}

The adsorption of the copper ion at various $\mathrm{pH}(3-7)$ was studied by using $10 \mathrm{mg}$ of c-MWCNTs. As shown in Figure $8 \mathrm{a}$, changes in $\mathrm{pH}$ influence adsorption by inducing a change in the charge on the surface of MWCNTs. The optimal $\mathrm{pH}$ for adsorption is 6 . At low $\mathrm{pH}, \mathrm{H}^{+}$inhibits carboxyl group dissociation and prevents the formation of $\mathrm{O}-$, COO-. As the $\mathrm{pH}$ rises, the $\mathrm{H}^{+}$content of the solution decreases, causing deprotenation of the c-MWCNT surface and an increase in adsorption sites, as well as facilitating the coordination of carboxyl groups with metal ions, resulting in an increase in adsorption capacity. (Jamnongkan et al., 2014). However, as the $\mathrm{pH}$ rises, the solution becomes increasingly alkaline. According to the metal ion dissolution precipitation curve, when $\mathrm{pH}>5$, some metal ions in the solution begin to precipitate, even though they are still mostly adsorbed. The precipitation trend intensifies as the $\mathrm{pH}$ rises, which is also the reason for the sharp drop in the adsorption effect of c-MWCNTs as the $\mathrm{pH}$ rises. (Najam et al., 2016).

Table 5. Maximum adsorption capacity of different carbon materials
Figure $8 \mathrm{~b}$ shows the effect of contact time (from 10-90 minutes) on adsorption efficiency, with c-MWCNTs dose $(10 \mathrm{mg})$, optimum $\mathrm{pH}=6$. the adsorption potential increased steadily as the contact time was increased until it reached a constant of 90 minutes. At the start of the reaction, the binding sites on c-MWCNTs were available to bind with copper ions, but as the contact time was increased, the binding sites were occupied and the equilibrium was reached (Oyetade et al., 2016).

\subsubsection{Effect of adsorbent dose and initial copper ions concentrations on the adsorption process}

The adsorbent dose is an important parameter to determine the free binding site that can bind with initial concentrations of ions. Figure $8 c$ exhibits the effect of cMWCNT dose (5-20 mg) on the adsorption capacity of copper ions at optimum $\mathrm{pH}=6$, and contact time $90 \mathrm{~min}$. The binding sites for copper ions increased by increasing the dose leading to adsorption capacity enhancement.

At optimum conditions, Figure $8 d$ shows the effect of initial $\mathrm{Cu}$ ions concentrations (50-500 ppm aqueous solution) on adsorption capability. According to the findings, increasing the concentration of $\mathrm{Cu}$ ions increased the adsorption capacity, demonstrating that the high affinity of c-MWCNT towered the adsorption of $\mathrm{Cu}$ ions and that as a result of their surface area.

\begin{tabular}{cccc}
\hline Adsorbent & Adsorption capacity $(\mathbf{m g} / \mathbf{g})$ & Adsorption technique & Ref \\
\hline C-MWCNT & 238.09 & $10 \mathrm{mg}$ & This work \\
\hline acid-chitosan-functionalized CNTs sheets & 57.34 & $50 \mathrm{mg}$ & Tofighy \& Mohammadi (2016) \\
\hline P-MWCNTs & 0.398 & $125 \mathrm{mg}$ & Abdel Salam (2013) \\
\hline MWCNTs-COOH & 49.1 & $30 \mathrm{mg}$ & Esmail \& Ebrahimi (2014) \\
\hline F-MWCNT & 118.41 & $10 \mathrm{mg}$ & Gupta et al. (2017) \\
\hline MWCNTs-COOH & 19.44 & $50 \mathrm{mg}$ & Oyetade et al.(2013)
\end{tabular}

Table 6. Fitting parameters for first and second order kinetic for adsorption of $\mathrm{Cu}$ (II) ion onto c-MWCNT

\begin{tabular}{lllllllll}
\hline \multirow{2}{*}{ Adsorbent } & \multirow{2}{*}{ q exp } & \multicolumn{2}{l}{ Pseudo-first order } & \multicolumn{4}{l}{ Pseudo-second order } \\
\cline { 3 - 8 } & & K & qe (cal) & $\mathbf{R}^{\mathbf{2}} \%$ & $\mathbf{K}_{\mathbf{2}}$ & qe (cal) & $\mathbf{R}^{\mathbf{2}} \%$ \\
\hline c- MWCNT & 133.3 & 0.034 & 74.47 & 0.876 & 0.0699 & 131.31 & 0.989 \\
\hline
\end{tabular}

\subsubsection{The adsorption isotherm of copper ions on c- MWCNT}

Figure 9a, b shows the adsorption isotherms resulting from the two models Langmuir and Freundlich. The correlation coefficient of the Langmuir model is greater than the correlation coefficient of the Freundlich model. As a result, the Langmuir model fits the $\mathrm{CU}$ (II) adsorption data better than the Freundlich model, and the maximum adsorption capacity was $238.09 \mathrm{mg} / \mathrm{g}$. This is consistent with the literature results, which show that the adsorption of $\mathrm{Cu}$ (II) on the other materials best fits the Langmuir model (Table 5).

\subsubsection{The adsorption kinetic of copper ions by c-MWCNT}

As confirmed by many studies, the adsorption kinetic data of heavy metals on CNTs are generally well described by the pseudo-second-order model (Sun et al., 2014). Also, from this study the adsorption mechanism can be better described by pseudo-second-order mechanism with good correlation, as shown by the high value of correlation coefficients (0.989) and the well fit to the measured $q$ with experimental results (Figure 10a and b, and Table 6). This suggests that chemisorption, in which valence forces are involved through electron sharing or exchange between the carboxyl (COOH) group and the $\mathrm{Cu}$ (II) ions, is the rate-limiting step for $\mathrm{Cu}$ (II) ions onto c-MWCNTs (Gupta et al., 2017).

\subsubsection{The proposed mechanism of $\mathrm{Cu}$ ions adsorption}

Electrostatic attraction, adsorption-precipitation, and chemical interaction between metal ions and CNT surface functional groups are some of the mechanisms for metals adsorbed by CNTs (Rao et al., 2007). The functionalization of the carbon surface can result in a surface structure that is both more hydrophilic and has a greater number of oxygen-containing functional groups. The complexation 
and decomplexation reactions are highly dependent on the functionalized groups and solution $\mathrm{pH}$ (Rao et al., 2007), and the chemical reaction between metal ions and the surface functional groups of CNTs is widely accepted as the major adsorption mechanism (Bystrzejewski and Pyrzyńska, 2011; Rosenzweig et al., 2013). In the current study, $\mathrm{Cu}$ ions exists mainly as a divalent ion $\left(\mathrm{Cu}^{2+}\right)$ at $\mathrm{pH}$ 6.0, whereas the carboxyl groups of c-MWCNT are deprotonated. $\mathrm{Cu}$ ions is adsorbed by c-MWCNTs by forming a complex with the carboxyl groups on their surface. Chemical complexation, rather than electrostatic attraction, appears to be the most important adsorption mechanism for $\mathrm{Cu}$ ions and c-MWCNT binding (Scheme 1).

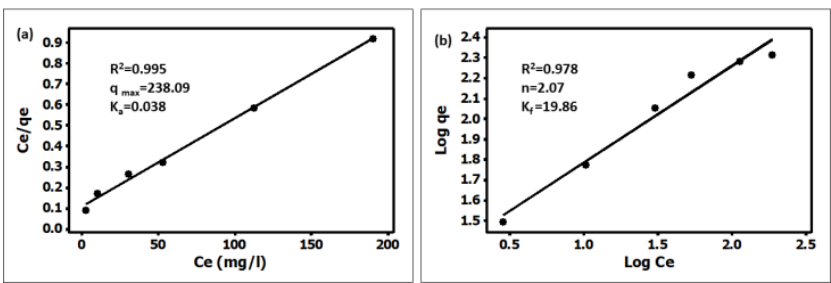

Figure 9. (a) Langmuir isotherm model for $\mathrm{Cu}$ (II) ion adsorption on $10 \mathrm{mg}$ c-MWCNTs, (b) Freundlich isotherm model for $\mathrm{Cu}$ (II) ion adsorption on $10 \mathrm{mg}$ c-MWCNTs.
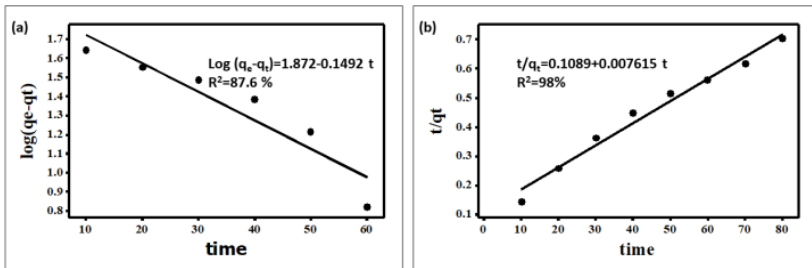

Figure 10 (a) Pseudo-first-order kinetic plot for $\mathrm{Cu}$ (II) ion adsorption on $10 \mathrm{mg}$ c-MWCNTs, (b) Pseudo-second-order kinetic plot for $\mathrm{Cu}$ (II) ion adsorption $10 \mathrm{mg}$ c-MWCNTs.

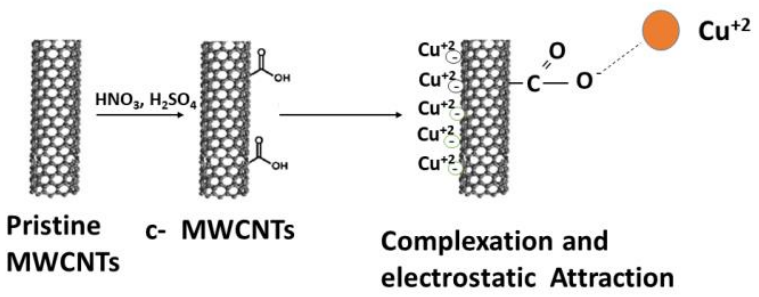

Scheme 1. The adsorption mechanism for $\mathrm{Cu}$ ions by c-MWCNT.

\subsubsection{Regeneration of c-MWCNT}

After using c-MWCNT as a $\mathrm{Cu}$ ion adsorbent, it was centrifuged and washed with diluted $\mathrm{HCl}(0.1 \mathrm{M})$ to extract $\mathrm{Cu}$ ions, washed with distilled water to neutralize the acid, and dried at $100^{\circ} \mathrm{C}$ to be ready for the second cycle of adsorption. The efficiency of c-MWCNT was found to be $83.5 \%$ after the first cycle, $63.1 \%$ after the second cycle, and $48.9 \%$ after the third cycle. This shows the effectiveness of the synthesized c-MWCNTs regeneration.

\section{Conclusion}

Because of their importance in a variety of uses and applications, there is a lot of interest in developing lowcost, high-yield, and high-quality MWCNTs. The catalyst $\mathrm{Fe} / \mathrm{Co}$ supported on aluminum oxide and zirconium oxide was used to synthesis MWCNTs, and the results were compared. Aluminum oxide and zirconium oxide were reported to be suitable supports for the growth of highquality MWNTs. The optimization of reaction parameters such as the reaction temperature, the gas flow rate, and the catalysts used and their supporting materials could result in MWCNTs with low impurities and high yield. The carbon nanotubes were synthesized in a web-like structure with a homogeneous distribution on the surface of the catalysts, as shown by SEM images. MWCNT grew from catalyst particles using a tip growth method, with an average diameter of 20-30 nm for MWCNT grown on alumina and 30-40 nm for MWCNT grown on zirconia, as seen in TEM images. The carboxylic groups on the MWCNTs were introduced to increase their adsorption efficiency for removing $\mathrm{Cu}$ ions from an aqueous solution as part of wastewater treatment. With a $k_{a}$ value of 0.038 and an $R^{2}$ value of 0.995 , the data fit best in the Langmuir model, and the adsorption of $\mathrm{Cu}$ (II) ion adopted the pseudo-second order model rather than the pseudo-firstorder model. The overall adsorption capacity of cMWCNTs was $238.09 \mathrm{mg} / \mathrm{g}$.

Conflicts of interest: There are no conflicts to declare.

\section{References}

Abbas A., Al-Amer A.M., Laoui T., Al-Marri M.J., Nasser M.S., Khraisheh M. and Atieh M.A. (2016), Heavy metal removal from aqueous solution by advanced carbon nanotubes: critical review of adsorption applications. Separation and Purification Technology, 157, 141-161.

Abdel Salam M. (2013), Removal of heavy metal ions from aqueous solutions with multi-walled carbon nanotubes: Kinetic and thermodynamic studies. International Journal of Environmental Science and Technology, 10, 677-688.

Ajitha P., Vijayalakshmi K., Saranya M., Gomathi T., Rani K., Sudha P.N. and Sukumaran A. (2017), Removal of toxic heavy metal lead (II) using chitosan oligosaccharide-graft-maleic anhydride/polyvinyl alcohol/silk fibroin composite. International Journal of Biological Macromolecules, 104, 14691482.

Anzar N., Hasan R., Tyagi M., Yadav N. and Narang J. (2020), Carbon nanotube - A review on Synthesis, Properties and plethora of applications in the field of biomedical science. Sensors International, 100003.

Arora B. and Attri P. (2020), Carbon nanotubes (CNTs): a potential nanomaterial for water purification., Journal of Computer Science, 4(3), 135.

Atchudan R., Cha B.G., Lone N., Kim J. and Joo J. (2019), Synthesis of high-quality carbon nanotubes by using monodisperse spherical mesoporous silica encapsulating iron oxide nanoparticles. Korean Journal of Chemical Engineering, 36, 157-165.

Banerjee D., Nguyen T. and Chuang T.J. (2016), Mechanical properties of single-walled carbon nanotube reinforced polymer composites with varied interphase's modulus and 
thickness: A finite element analysis study. Computational Materials Science, 114, 209-218.

Burakova E.A., Dyachkova T.P., Rukhov A.V., Tugolukov E.N., Galunin E.V., Tkachev A.G., Basheer A.A. and Ali I. (2018), Novel and economic method of carbon nanotubes synthesis on a nickel magnesium oxide catalyst using microwave radiation. Journal of Molecular Liquids, 253, 340-346.

Bystrzejewski M. and Pyrzyńska K. (2011), Kinetics of copper ions sorption onto activated carbon, carbon nanotubes and carbon-encapsulated magnetic nanoparticles. Colloids and Surfaces A: Physicochemical and Engineering Aspects, 377, 402-408.

Calafat A. (1998), The influence of preparation conditions on the surface area and phase formation of zirconia. Studies in Surface Science and Catalysis, 118, 837-843. Elsevier.

Cassell A.M., Raymakers J.A., Kong J. and Dai H. (1999), Large scale CVD synthesis of single- walled carbon nanotubes. Journal of Physical Chemistry. B, 103, 6484-6492.

Chen L., Xin H., Fang Y., Zhang C., Zhang F., Cao X., ... and Li X. (2014), Application of metal oxide heterostructures in arsenic removal from contaminated water. Nanomaterials, 2014.

Colomer J., Stephan C., Lefrant S., Van Tendeloo G., Willems I., Onya Z.K. and Fonseca A.C.J.B. (2000), Large-scale synthesis of single-wall carbon nanotubes by catalytic chemical vapor deposition (CCVD) method. Chemical Physics Letters, 317, 83-89.

Dhorea V.G., Rathodb W.S. and Patil K.N. (2018), Synthesis and characterization of high yield multiwalled carbon nanotubes by ternary catalyst. Material Today, 5, 3432-3437.

Du R., Wu J., Chen L., Huang H., Zhang X. and Zhang J. (2014), Hierarchical hydrogen bonds directed multi-functional carbon nanotube-based supramolecular hydrogels. Small, 10(7), 1387-1393.

El-Maghraby A., El-Deeb H.A. and Khattab M.A. (2014). Influence of $\mathrm{FeNi} / \mathrm{Al}_{2} \mathrm{O}_{3}$ Catalyst Compositions on the Growth of Carbon Nanotubes. Fullerenes Nanotubes and Carbon Nanostructures, 23, 27-34.

Ertan B., Eren T., Ermiş I., Saral H., Atar N. and Yola M. (2016), Sensitive analysis of simazine based on platinum nanoparticles on polyoxometalate/multi-walled carbon nanotubes. Journal of Colloid and Interface Science, 470, 1421.

Fischer J.E. (2006), Carbon nanotubes: structures and properties, in: Y. Gogotsi (Ed.), Nanotubes and Nanofibers, Taylor and Francis, CRC Press, New York, p. 1-36.

Fonseca A., Hernadi K., Piedigrosso P., Colomer J.-F., Mukhopadhyay K., Doome R., Lazarescu S., Biro L.P., Lambin P., Thiry P.A., Bernaerts D. and Nagy J.B. (1998), Synthesis of single- and multi-wall carbon nanotubes over supported catalysts. Applied Physics A, 67(1), 11-12.

Freundlich H.M.F. (1906), Uber die adsorption in losungen. Zeitschrift für Physikalische Chemie (Leipzig), 57, 385-470.

Gopalan R., Chang C.-H. and Lin Y.S. (1995) Thermal stability improvement on pore and phase structure of sol-gel derived zirconia. Journal of Materials Science, 30, 3075-3081.

Grover V., Shukla R. and Tyagi A.K. (2007), Facile synthesis of $\mathrm{ZrO}_{2}$ powders: Control of morphology. Scripta Materialia, 57(8), 699-702.

Gupta V. and Saleh T.A. (2011), synthesis of carbon nanotubemetal oxide composite: adsorption and photo degradation; DOI: $10.5772 / 18009$.
Hanbali G., Jodeh S., Hamed O., Bol R., Khalaf B., Qdemat A., ... and Dagdag, $O$ (2020), Magnetic multiwall carbon nanotube decorated with novel functionalities: synthesis and application as adsorbents for lead removal from aqueous medium. Processes, 8(8), 986.

Hole R., Munde A. and Jaybhaye S. (2021), Functionalization of multiwalled carbon nanotubes with active pharmaceutical ingredient via carboxylation. Materials Today: Proceedings, 45, 3860-3862.

Hussain M., Begum S.S., Kalita M.K., Ahmed K.U. and Nath R. (2018), Additives used in semen preservation in animals: A short review. International Journal of Chemical Studies, 6(5), 354-361.

Hussein M.Z., Jaafar A.M., Yahaya A.H., Masarudin M.J. and Zainal Z. (2014), formation and yield of multi-walled carbon nanotubes synthesized via chemical vapour deposition routes using different metal-based catalysts of FeCoNiAl, CoNiAl and FeNiAl-LDH. International Journal of Molecular Sciences, 15, 20254-20265.

Ihsanullah I., Sajid M., Kabeer M., Shemsi A.M. and Atieh M.A. (2020), First investigations on the removal of tungsten species from water using multi-walled carbon nanotubes. Water, Air, and Soil Pollution, 231(3), 1-11.

Jamnongkan T., Kantarot K., Niemtang K., Pansila P.P. and Wattanakornsiri A. (2014), Kinetics and mechanism of adsorptive removal of copper from aqueous solution with poly (vinyl alcohol) hydrogel. Transactions of Nonferrous Metals Society of China, 24(10), 3386-3393.

Karimi-Maleh H., Tahernejad-Javazmi F., Atar N., Yola M., Gupta V. and Ensafi A. (2015) A novel DNA biosensor based on a pencil graphite electrode modified with polypyrrole/functionalized multiwalled carbon nanotubes for determination of 6-mercaptopurine anticancer drug. Industrial and Engineering Chemistry Research, 54, 36343639.

Kathyayini H.N., Nagaraju N., Fonseca A., and Nagy J.B. (2004), Catalytic activity of $\mathrm{Fe}, \mathrm{Co}$ and $\mathrm{Fe} / \mathrm{Co}$ supported on $\mathrm{Ca}$ and $\mathrm{Mg}$ oxides, hydroxides and carbonates in the synthesis of carbon nanotubes. Journal of Molecular Catalysis A: Chemical, 223, 129-136.

Lagergren S. (1898), About the theory of so-called adsorption of soluble substances. Kungliga Svenska Vetenskapsakademiens Handlingar, 24, 1-39.

Langmuir I. (1916). The constitution and fundamental properties of solids and liquids. Journal of the American Chemical Society, 38, 2221-2295.

Maruyama S., Murakami Y., Shibuta Y., Miyauchi Y. and Chiashi S. (2004) generation of single-walled carbon nanotubes from alcohol and generation mechanism by molecular dynamics simulations., Journal of Nanoscience and Nanotechnology, 4(4), 360-367.

Mohammed I.A., Bankole M.T., Abdulkareem A.S., Ochigbo S.S., Afolabi A.S. and Abubakre O.K. (2017), Full factorial design approach to carbon nanotubes synthesis by CVD method in argon environment, South African Journal of Chemical Engineering, 24, 17-42.

Mwafy E.A. and Mostafa A.M. (2020), Tailored MWCNTs $/ \mathrm{SnO}_{2}$ decorated cellulose nanofiber adsorbent for the removal of $\mathrm{Cu}$ (II) from wastewater. Radiation Physics and Chemistry, 177, 109172. 
Najam R., Muzaffar S. and Andrabi A. (2016), Removal of Cu(II), $\mathrm{Zn}$ (II) and $\mathrm{Cd}(\mathrm{II})$ ions from aqueous solutions by adsorption on walnut shell-Equilibrium and thermodynamic studies: treatment of effluents from electroplating industry. Desalination and Water Treatment, 57, 27363-27373.

Oyetade O.A., Nyamori V.O., Martincigh B.S. and Jonnalagadda S.B. (2016), Nitrogen-functionalised carbon nanotubes as a novel adsorbent for the removal of $\mathrm{Cu}(\mathrm{II})$ from Aqueous solution. RSC Advances, 6, 2731.

Patel J., Parikh S., Patel S., Patel R. and Patel P. (2021), Carbon nanotube (CNTs): structure, synthesis, purification, functionalisation, pharmacology, toxicology, biodegradation and application as nanomedicine and biosensor: carbon nanotube (CNTs). Journal of Pharmaceutical Sciences and Research, 1(2), 17-44.

Peigney A., Laurent Ch., Dobingeon F. and Rousset A. (1997), Carbon nanotubes grown in situ by a novel catalytic method. Journal of Material Research, 12, 613-615.

Pham Q.L., Haldorai Y., Nguyen V.H., Tuma D. and Shim J. (2011), Facile synthesis of poly(p-phenylenediamine)/MWCNT nanocomposites and characterization for investigation of structural effects of carbon nanotubes. Bulletin of Materials Science, 34, 37-43.

Qingwen L., Hao Y., Yan C., Jin Z. and Zhongfan L. (2002), A scalable CVD synthesis of high-purity single-walled carbon nanotubes with porous $\mathrm{MgO}$ as support material. Journal of Materials Chemistry, 12, 1179-1183.

Rao G.P., Lu C., Su F. (2007). Sorption of divalent metal ions from aqueous solution by carbon nanotubes: a review, Separation and Purification Technology, 58, 224-231.

Rosenzweig S., Sorial G.A., Sahle-Demessie E. and Mack J. (2013), Effect of acid and alcohol network forces within functionalized multiwall carbon nanotubes bundles on adsorption of copper (II) species, Chemosphere, 90, 395-402.

Sari A.H., Khazali A. and Parhizgar S.S. (2018), Synthesis and characterization of long-CNTs by electrical arc discharge in deionized water and $\mathrm{NaCl}$ solution, International Nano Letters, 8, 19-23.

Tofighy M.A. and Mohammadi T. (2016), Copper ions removal from aqueous solutions using acid-chitosan functionalized carbon nanotubes sheets. Desalination and Water Treatment, 57(33), 15384-15396.

Wang J., Shen B., Lan M., Kang D. and Wu C. (2020), Carbon nanotubes (CNTs) production from catalytic pyrolysis of waste plastics: The influence of catalyst and reaction pressure. Catalysis Today, 351, 50-57.

Wang Z., Xu W., Jie F. et al. (2021), The selective adsorption performance and mechanism of multiwall magnetic carbon nanotubes for heavy metals in wastewater. Scientific Reports, 11, 16878.

Yan Y.H., Cui J., Chan-Park M.B., Wang X. and Wu Q.Y. (2007), systematic studies of covalent functionalization of carbon nanotubes via argon plasma-assisted UV grafting. Nanotechnology, 18, 24-42.

Yang Y., Zhang H. and Yan Y. (2019), Synthesis of CNTs on stainless steel microfibrous composite by CVD: effect of synthesis condition on carbon nanotube growth and structure. Composites Part B: Engineering, 160, 369-383.

Yola M. and Necip Atar N. (2014a), A novel voltammetric sensor based on gold nanoparticles involved in $\mathrm{p}$-aminothiophenol functionalized multi-walled carbon nanotubes: Application to the simultaneous determination of quercetin and rutin. Electrochimica Acta, 119, 24-31.

Yola M., Eren T. and Atar N. (2014b), Molecularly imprinted electrochemical biosensor based on $\mathrm{Fe} / \mathrm{Au}$ nanoparticles involved in 2-aminoethanethiol functionalized multi-walled carbon nanotubes for sensitive determination of cefexime in human plasma. Biosensor Bioelectronics, 60, 277-285. 